\title{
Recht
}

\section{Ärzte sollten Arztsitz gegen MVZ-Pleite absichern}

\author{
In einem medizinischen Versorgungszentrum tätige Ärzte sollten \\ überlegen, eine Klausel zur Insolvenz ihrer Einrichtung in den \\ Arbeitsvertrag einzubringen. Im Ernstfall hat das Vorteile für den \\ Erhalt des Arztsitzes, wie ein neues BSG-Urteil nahelegt.
}

A rzt sein ohne unternehmerischen Ballast - als Angestellter im medizinischen Versorgungszentrum (MVZ) ist das möglich. Gleichzeitig bedeutet die Tätigkeit in einem MVZ dann aber auch, dass die rechtlichen Folgen beispielsweise einer Insolvenz des MVZ-Trägers arbeitsrechtlicher Natur

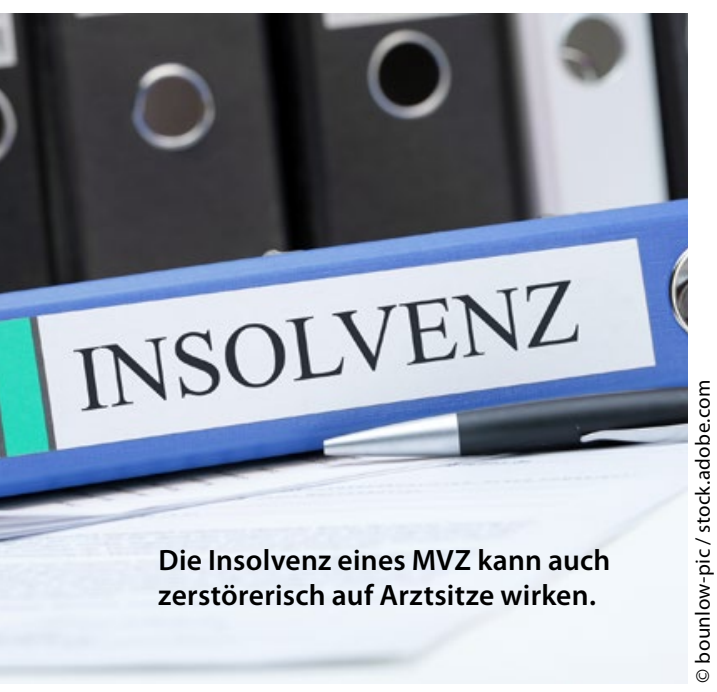

sind - Ärzte sollten deshalb vor ihrer Unterschrift unter den Arbeitsvertrag an die Möglichkeit einer Insolvenz denken. Das zeigt ein aktuelles Urteil des Bundessozialgerichts (BSG) zur Insolvenz des MVZ am Rosa-Luxemburg-Platz (ehemals AtrioMed) in Berlin.

AtrioMed war mehrfach in die Schlagzeilen geraten. 2008 hatte es in großem Stil unter erfundenen Arztnummern ab- gerechnet. Bis hinauf zum Bundesverfassungsgericht stand daher durch alle Instanzen der Zulassungsentzug außer Frage. Die „massiven Unregelmäßigkeiten“ betrafen „unmittelbar die Organisation des MVZ", betonte damals das BSG. Anfang 2012 wurde das Insolvenzverfahren eröffnet. Nach Berechnung des Insolvenzverwalters war bis Ende 2011 ein Defizit von über 1,4 Million Euro aufgelaufen. Ohne Zulassung mussten die angestellten Ärzte entlassen werden. Ende Juni 2012 stellte das MVZ den Betrieb ein.

\section{KV Berlin hatte geklagt}

In dem neuen Streit ging es nun darum, was mit den Vertragsarztsitzen des MVZ geschieht. Der Insolvenzverwalter wollte sie in Einzelzulassungen umwandeln und zugunsten der Insolvenzmasse verkaufen. Nachdem sich im Oktober 2012 auch die Betreibergesellschaft dem angeschlossen hatte, gab der Berufungsausschuss dem Umwandlungsantrag statt. Die Kassenärztliche Vereinigung (KV) Berlin war damit nicht einverstanden und klagte. Der Insolvenzverwalter sei gar nicht befugt, einen solchen Umwandlungsantrag zu stellen. Und ohnehin sei der Antrag im Oktober 2012 viel zu spät erfolgt. Denn mit Einstellung seiner Tätigkeit am 30. Juni 2012 sei das MVZ samt seiner Arztsitze untergegangen. Dem ist der BSG-Vertragsarztsenat nun im Ergebnis gefolgt (Az.: B 6 KA 27/16 R).

Es bestehe eine „strenge Akzessualität“ zwischen MVZ-Zulassung und
Arztsitzen: „Nach Ende der Zulassung kann die Umwandlung nicht mehr beantragt werden." Die Zulassung sei hier auch zum 30. Juni 2012 erloschen, denn das MVZ habe sich zu diesem Zeitpunkt „aufgelöst“. Bezugspunkt sei dabei „die tatsächliche Möglichkeit zur Teilnahme an der Versorgung“. Hier seien Ende Juni 2012 keine Ärzte mehr tätig und eine Nachbesetzung nicht beabsichtigt gewesen. Damit sei die Auflösung eingetreten.

Die Kasseler Richter stellten klar, dass der Insolvenzverwalter keinen Umwandlungsantrag mehr stellen kann. Parallel zur Kündigung der angestellten Ärzte müsse vielmehr der MVZ-Betreiber gegenüber den Zulassungsgremien einen solchen Antrag zumindest ankündigen. „Wer das nicht macht, hat die Zulassung verwirkt", stellte der Senatsvorsitzende Ulrich Wenner klar.

\section{Klausel als Chance}

Für MVZ-Ärzte bietet sich als Konsequenz an, in den Arbeitsvertrag eine Klausel zur Insolvenz aufzunehmen. Darin könnte sich der MVZ-Betreiber verpflichten, im Fall einer insolvenzbedingten Kündigung sofort auch die Umwandlung des betreffenden Arztsitzes in eine Einzelzulassung zu beantragen. Der Sitz müsste dann zwar ausgeschrieben werden, bei Interesse hätte der geschasste MVZ-Arzt dann aber sicherlich gute Chancen, den Zuschlag zu bekommen.

Das BSG hatte hierzu freilich nicht zu entscheiden. Es hatte lediglich bereits früher angedeutet, dass es eine Perspektive für den Arzt geben muss, wenn er seinen Sitz noch selbst in das MVZ eingebracht hat. Das war hier bei den entlassenen Ärzten jedoch nicht mehr der Fall.

Martin Wortmann 